\title{
A Randomized Controlled Trial Depicting Postoperative Pain Score Following Port-site Infiltration during Laparoscopy
}

\author{
Tanzeem S Chowdhury ${ }^{1}$, Mehnaz Mustary², Towhidul Anowar Chowdhury ${ }^{3}$
}

\begin{abstract}
Aim: This study was aimed to determine the efficacy of local bupivacaine injection into the incision site before diagnostic laparoscopy to reduce postoperative pain among infertile patients.

Materials and methods: This was a randomized controlled study on 168 consecutive infertile women who underwent diagnostic laparoscopy at Farida Clinic and Infertility Management Center, Dhaka, from February to November 2018. Twenty-two patients were excluded from the study due to not meeting the criteria and 144 patients were finally taken for randomization.

Results: In this study, majority of patients $(n=79)$ belonged to age $21-30$ years. The mean age was found to be $29.7 \pm 4.5$ years in group I and $30.2 \pm 4.7$ years in group II. Majority of the patients had primary infertility in both groups, which was 47 (65.3\%) in group I and 57 (79.2\%) in group II. The commonest comorbidity was hypothyroidism found in both groups, 9 (12.5\%) in group I and 7 (9.7\%) in group II. Nine (12.5\%) patients had previous operation in group I and $13(18.1 \%)$ in group II. This study showed that majority of patients had mild pain 1 hour after surgery-48 (66.7\%) in group I and $50(69.4 \%)$ in group II. Three hours after surgery majority of patients in both groups had no pain $43(59.7 \%)$ in group I and 40 (55.6\%) in group II. Twelve hours after surgery, there was no pain in 64 patients (88.9\%) in group I and 65 patients (90.3\%) in group II. After 7 days of surgery, postoperative pain was absent in 45 (62.5\%) patients in group I and 42 (58.3\%) patients in group II, respectively. Conclusion: Considering the result of the study, at 1,3,12 hours and 7 days after surgery, pain score was not statistically significant $(p>0.05)$ between intervention and nonintervention groups. So, port-site infiltration of bupivacaine does not reduce the postoperative pain following laparoscopy.

Keywords: Bupivacaine, Laparoscopy, Port-site pain, Postoperative analgesics.

Journal of South Asian Federation of Obstetrics and Gynaecology (2019): 10.5005/jp-journals-10006-1693
\end{abstract}

\section{INTRODUCTION}

Diagnostic laparoscopy has been an invaluable tool for the evaluation and management of infertility for the last two decades. There are several advantages like smaller and more cosmetic incision, reduced blood loss, shorter postoperative stay, and early resumption of normal activities. But despite the minimally invasive nature of this surgery, there remain some challenges to minimize the postoperative pain following laparoscopy. Uncontrolled postoperative pain has an adverse sequel of delayed resumption of normal pulmonary function and restriction of mobility leading to increased risk of thromboembolism. There may also be an increase in the systemic vascular resistance, cardiac work, and myocardial oxygen consumption induced by the stress response. ${ }^{1}$ So, improving postoperative pain control has become an increasingly important issue for the surgeon and anesthesiologist. $^{2}$

Postoperative pain following laparoscopy is usually multifactorial. The pain that arises from port sites is somatic pain and pain that occurs due to distention of the abdominal cavity by pneumoperitoneum, and surgical handling is visceral pain. The third type of pain is the referred pain, which is felt in the shoulder tip due to gaseous distention. ${ }^{3}$ Recent advances suggest that an afferent block (with local anesthetics) achieved before nociceptive input can reduce or eliminate the onset of central neural hyperexcitability and can thus significantly reduce both intensity and duration of postoperative pain. ${ }^{4}$ Preemptive local anesthesia, therefore, may be more effective than postoperative analgesic administration at preventing postoperative pain. Bupivacaine is one such local anesthetic, which has a good safety profile, is long-acting and free
${ }^{1,3}$ Department of Obstetrics and Gynecology, Bangladesh Institute of Research \& Rehabilitation in Diabetes, Endocrine and Metabolic Disorders, General Hospital and Ibrahim Medical College, Shahbagh, Dhaka, Bangladesh

${ }^{2}$ Department of Obstetrics and Gynecology, Panchbibi Upazila Health Complex, Joypurhat, Bangladesh

Corresponding Author: Tanzeem S Chowdhury, Department of Obstetrics and Gynecology, Bangladesh Institute of Research \& Rehabilitation in Diabetes, Endocrine and Metabolic Disorders, General Hospital and Ibrahim Medical College, Shahbagh, Dhaka, Bangladesh, Phone: +880 1713037853, e-mail: tanzeemsc@gmail.com

How to cite this article: Chowdhury TS, Mustary M, Chowdhury TA. A Randomized Controlled Trial Depicting Postoperative Pain Score Following Port-site Infiltration during Laparoscopy. J South Asian Feder Obst Gynae 2019;11(4):230-234.

Source of support: Nil

Conflict of interest: None

of side effects like nausea and vomiting due to NSAIDs and fears of drug dependence as in case of opioids. It has a half-life of 2.5-3.5 hours and has been reported to provide pain control for an average of 6 hours. ${ }^{5}$ Present study is designed to evaluate the effect of subcutaneous administration of $0.25 \%$ bupivacaine for pain relief before diagnostic laparoscopy in infertile patients.

\section{ОвJective}

To determine the efficacy of local bupivacaine injection into the incision site before diagnostic laparoscopy to reduce postoperative pain among infertile patients. 


\section{Materials and Methods}

The study population was 168 infertile women who underwent diagnostic laparoscopy at Farida Clinic and Infertility Management Center, a Dhaka-based tertiary care setup for infertility management and assisted reproduction.

Data were collected from February 2018 to November 2018. Prior approval was obtained from the ethical committee of the center.

\section{Inclusion and Exclusion Criteria}

The present study included women who were more than 18 years of age and had infertility of more than 1 year. All participating patients were either ASA score I and II. Those patients, who had a contraindication to bupivacaine, were ASA score III or more or had been suffering from chronic pelvic pain and used NSAIDs and other analgesics for a long time and those who were diagnosed with moderate to severe endometriosis were excluded from the study. According to those criteria, 22 patients were excluded from the study, and 144 patients were taken for randomization.

\section{Methods}

Preoperatively, all the patients were explained about the study, and written consent was obtained. Then they were explained about the visual analog scale (VAS) to indicate their pain perception by identifying zero as no pain and 10 as worst imaginable pain.

The study population was then equally divided into two groups. Group I (72 patients with even numbers) was the intervention group, and group II (72 patients with odd numbers) was the nonintervention group (Flowchart 1).

A standard general endotracheal anesthesia protocol was used for all patients. Group I received $10 \mathrm{~mL}$ of $0.25 \%$ bupivacaine, which was injected into the $10 \mathrm{~mm}$ central port site through all preperitoneal layers before incision (Fig. 1). Group II received no bupivacaine. Laparoscopic procedure was carried out by direct entry method with $\mathrm{CO}_{2}$ insufflations. During laparoscopy, the intra-abdominal pressure was limited to $12-14 \mathrm{~mm} \mathrm{Hg}$.
The operative procedures performed included ovarian drilling, ovarian cystectomy, adhesiolysis, salpingectomy, salpingostomy, cyst aspirations, and fulguration of mild endometriosis. All patients were operated by the same surgical team with a standard number of ports and surgical steps. All patients received one stick of diclofenac suppository postoperatively as per protocol of the center.

To evaluate postoperative pain, the patients were asked to rate the intensity of pain using the VAS ranging from 1 (absence of pain) to 10 (worst pain possible) 1 hour after the surgery in the postoperative room and at 3 and 12 hours (Fig. 2). Rescue analgesics injection tramadol $50 \mathrm{mg}$ IM was given when there was severe pain (VAS score $>6$ ). The patients were discharged as per the center's day case surgery guidelines. They were again followed up 7 days after surgery and asked to rate the intensity of pain. The time and dosage of additional analgesia were recorded if administered.

Primary outcome was postoperative pain scores using the VAS. Secondary outcomes were operating time (initial incision to skin closure), additional analgesic requirements, and perioperative complications like vomiting and shoulder tip pain.

Descriptive statistics, i.e., mean, median, range and distribution with their percentage were described for the variable included in the study. To obtain a significant difference for pain scores (VAS) between both groups, both unpaired $t$ test and Chi-square test were used. A $p$ value of 0.05 has been considered as a level of statistical significance. All statistical analysis was done using SPSS version 23.

\section{Results}

Present study showed majority of patients $(n=79)$ belonged to age $21-30$ years in both groups, which was 42 (58.3\%) in group I (receiving bupivacaine) and 37 (51.4\%) in group II (not receiving bupivacaine). The mean age was found to be $29.7 \pm 4.5$ years in group I and $30.2 \pm 4.7$ years in group II. The mean age was not statistically different ( $p>0.05$ ) between the two groups (Fig. 3). Majority of the patients had primary infertility in both groups, which was 47 (65.3\%) in group I and 57 (79.2\%) in group II.

Flowchart 1: Showing methodology

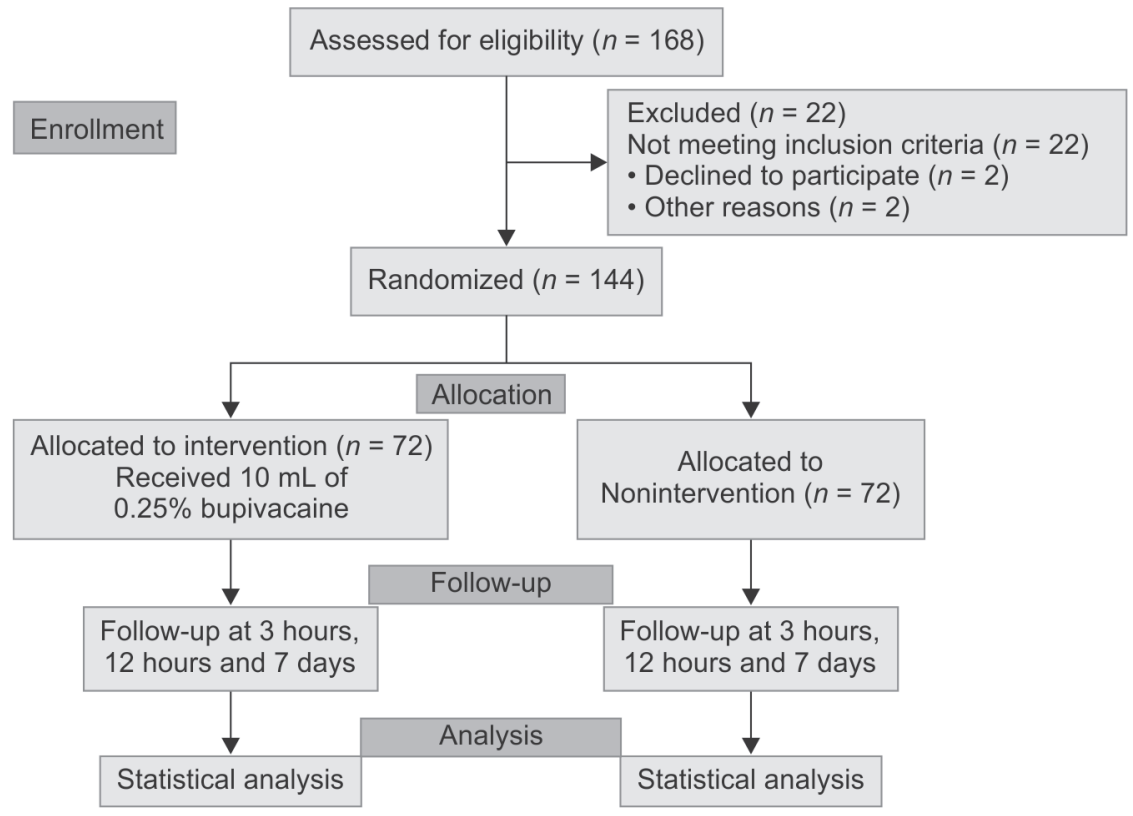




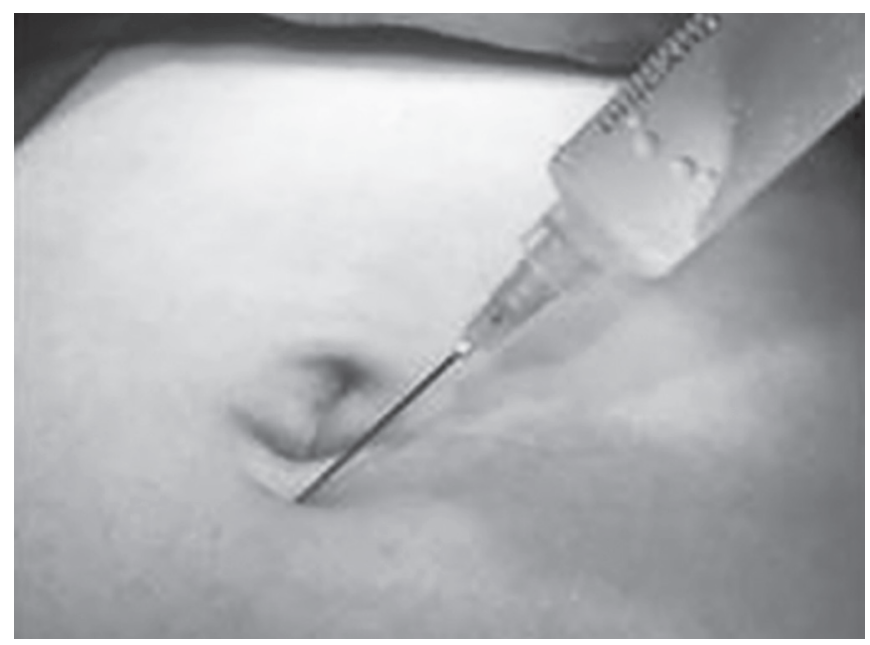

Fig. 1: Wound infiltration with $10 \mathrm{~mL}$ of $0.25 \%$ bupivacaine around the umbilicus just before incision

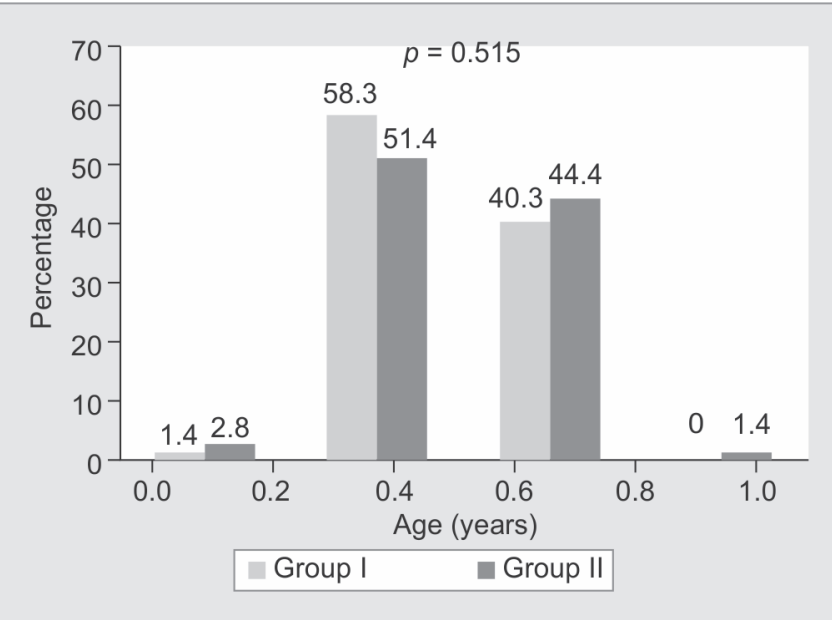

Fig. 3: Distribution of the study patients by age $(n=144)$

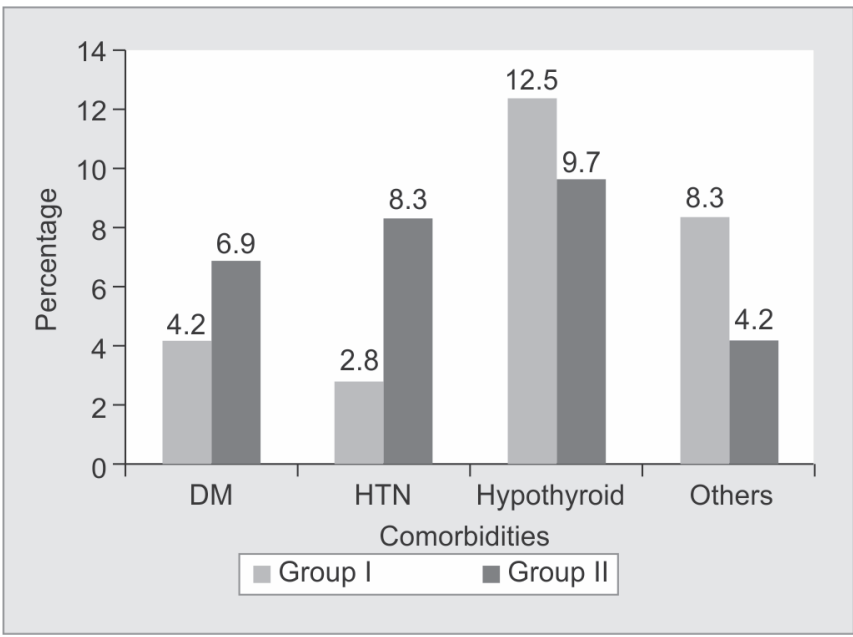

Fig. 5: Distribution of the study patients according to comorbidities $(n=144)$

Secondary infertility was 25 (34.7\%) and 15 (20.8\%) in group I and group II, respectively. The difference was not statistically significant $(p>0.05)$ between two groups (Fig. 4). Regarding associated

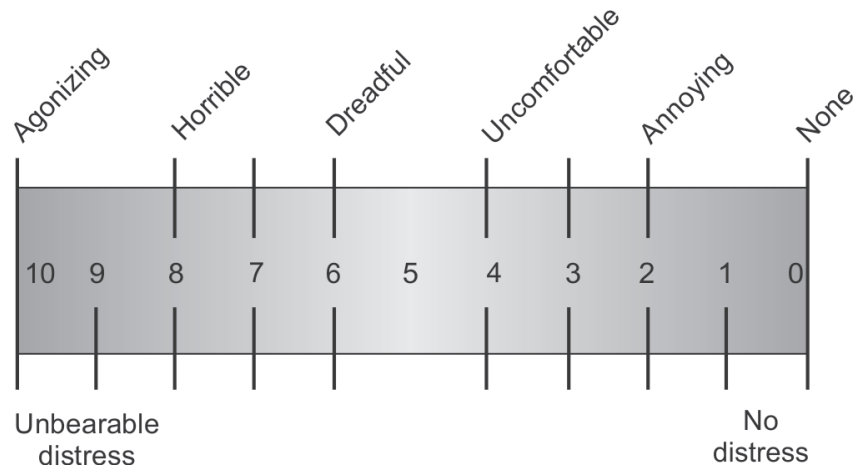

Fig. 2: Visual analog scale

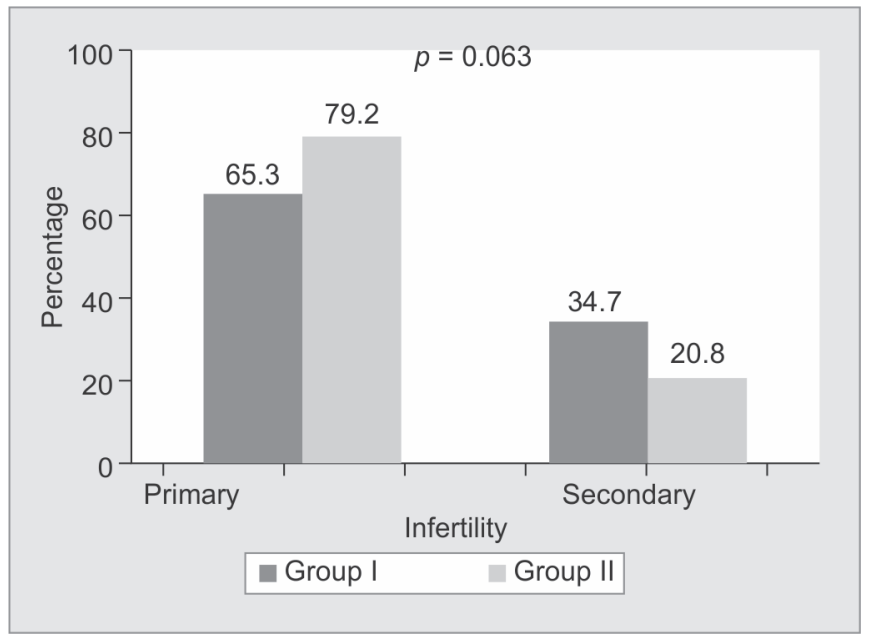

Fig. 4: Distribution of the study patients according to infertility $(n=144)$

comorbidities, the commonest comorbidity was hypothyroidism found in both groups, 9 (12.5\%) in group I and 7 (9.7\%) in group II. Other comorbidities were not statistically significant $(p>0.05)$ between two groups (Fig. 5). Nine (12.5\%) patients had the previous operation in group I and $13(18.1 \%)$ in group II (Table 1). The mean duration of the operative procedure was comparable with $26.1 \pm$ 5.9 minutes in group I and $26.3 \pm 6.3$ minutes in group II (Table 2).

When VAS score was compared between two groups in the present study, majority of patients had mild pain 1 hour after surgery-48(66.7\%) in group I and 50 (69.4\%) in group II (Table 3).

Three hours after surgery, the majority of patients in both groups had no pain $43(59.7 \%)$ in group I and 40 (55.6\%) in group II. Twelve hours after surgery, just before the patients were discharged from the hospital, no pain was found in 64 patients (88.9\%) in group I and 6 patients 5 (90.3\%) in group II. When the patients came for follow-up 7 days after surgery, no pain was observed 45 (62.5\%) and 42 (58.3\%) in group I and group II, respectively. So, at 1, 3, 12 hours, and 7 days after surgery, the pain score was not statistically

Table 1: Distribution of the study patients according to previous operation $(n=144)$

\begin{tabular}{|c|c|c|c|c|c|}
\hline \multirow{2}{*}{$\begin{array}{l}\text { Previous } \\
\text { operation }\end{array}$} & \multicolumn{2}{|c|}{ Group I $(n=72)$} & \multicolumn{2}{|c|}{ Group II $(n=72)$} & \multirow[b]{2}{*}{$p$ value } \\
\hline & $n$ & $\%$ & $n$ & $\%$ & \\
\hline Present & 9 & 12.5 & 13 & 18.1 & $0.354^{\mathrm{ns}}$ \\
\hline Absent & 63 & 87.5 & 59 & 81.9 & \\
\hline
\end{tabular}

ns $=$ not significant

$p$ value reached from Chi-square test 
Table 2: Distribution of the study patients according to operation duration $(n=144)$

\begin{tabular}{|c|c|c|c|c|c|}
\hline \multirow{2}{*}{$\begin{array}{l}\text { Operation duration } \\
\text { (minute) }\end{array}$} & \multicolumn{2}{|c|}{ Group I $(n=72)$} & \multicolumn{2}{|c|}{ Group II $(n=72)$} & \multirow[b]{2}{*}{$p$ value } \\
\hline & $n$ & $\%$ & $n$ & $\%$ & \\
\hline$\leq 30$ & 66 & 91.7 & 67 & 93.1 & \\
\hline$>30$ & 6 & 8.3 & 5 & 6.9 & \\
\hline Mean \pm SD & \multicolumn{2}{|c|}{$26.1 \pm 5.9$} & \multicolumn{2}{|c|}{$26.3 \pm 6.3$} & $0.844^{\mathrm{ns}}$ \\
\hline Range (min-max) & \multicolumn{2}{|c|}{$15-45$} & \multicolumn{2}{|c|}{$15-45$} & \\
\hline
\end{tabular}

ns $=$ not significant

$p$ value reached from unpaired $t$ test

Table 3: Pain (visual analog scale) score in different follow-ups $(n=144)$

\begin{tabular}{|c|c|c|c|c|c|}
\hline \multirow[b]{2}{*}{ Pain (VAS) score } & \multicolumn{2}{|c|}{ Group I $(n=72)$} & \multicolumn{2}{|c|}{ Group II $(n=72)$} & \multirow[b]{2}{*}{$p$ value } \\
\hline & $n$ & $\%$ & $n$ & $\%$ & \\
\hline \multicolumn{6}{|l|}{1 hour after surgery } \\
\hline None (0) & 22 & 30.6 & 20 & 27.8 & \\
\hline Mild (1-3) & 48 & 66.7 & 50 & 69.4 & $0.934^{\mathrm{ns}}$ \\
\hline Moderate (4-7) & 2 & 2.8 & 2 & 2.8 & \\
\hline \multicolumn{6}{|c|}{3 hours after surgery } \\
\hline None (0) & 43 & 59.7 & 40 & 55.6 & \\
\hline Mild (1-3) & 26 & 36.1 & 31 & 43.1 & $0.467^{\mathrm{ns}}$ \\
\hline Moderate (4-7) & 1 & 1.4 & 1 & 1.4 & \\
\hline Severe (8-10) & 2 & 2.8 & 0 & 0.0 & \\
\hline \multicolumn{6}{|c|}{12 hours after surgery } \\
\hline None (0) & 64 & 88.9 & 65 & 90.3 & $0.785^{\mathrm{ns}}$ \\
\hline Mild (1-3) & 8 & 11.1 & 7 & 9.7 & \\
\hline \multicolumn{6}{|l|}{7 days after surgery } \\
\hline None (0) & 45 & 62.5 & 42 & 58.3 & \\
\hline Mild (1-3) & 25 & 34.7 & 29 & 40.3 & $0.693^{\mathrm{ns}}$ \\
\hline Moderate (4-7) & 2 & 2.8 & 1 & 1.4 & \\
\hline
\end{tabular}

ns = not significant

$p$ value reached from Chi-square test

significant $(p>0.05)$ between intervention and nonintervention groups.

Regarding the secondary outcomes, two patients received Inj. tramadol as additional analgesics in group I in the present study. No significant perioperative complication developed in either group during the early follow-up period.

\section{Discussion}

Postoperative pain is the main factor delaying the discharge of patients undergoing day-care procedures such as laparoscopy, which adds to hospital cost. So, search for an optimum regime of pain relief in the postoperative period is going on, and many analgesics have been investigated by the surgeons and the anesthetists. Local anesthetic agents have a shorter analgesic effect, which lasts for a few hours; they have minimal sedative effects, and also have fewer side effects like nausea and vomiting commonly encountered after GA. ${ }^{6}$ So, they may be an ideal agent to enable the patient for early discharge from the hospital following laparoscopic surgery.

There have been numerous studies in the last few years about the use of local anesthetics as preemptive analgesia, which can be applied by using many methods, such as spinal blocks, epidural blocks, and preincisional infiltration. Several kinds of local anesthetics, such as lidocaine, bupivacaine, levobupivacaine, and ropivacaine, have been used for wound infiltration to provide postoperative pain relief.

In our study, the intervention group received $10 \mathrm{~mL}$ of $0.25 \%$ bupivacaine, which was injected into the $10 \mathrm{~mm}$ trocar entry port site before the operation and was compared with the nonintervention group who received no bupivacaine. The results showed that at $1,3,12$ hours, and 7 days after surgery, the pain score was not statistically significant $(p>0.05)$ between intervention and nonintervention groups. Chundrigar et al. in 1993 in a randomized trial in England used the same dose ( $0.25 \%$ bupivacaine) and showed decreased postoperative pain 1-2 hours after laparoscopic surgery; however, analgesic consumption over the next 24 hours was the same in the control study. ${ }^{7}$ A more recent study by Agrawal in 2017 also showed that there was no significant difference in postoperative pain scores between bupivacaine and control group in the immediate postoperative period following laparoscopic cholecystectomy. ${ }^{8}$

This is in contrast to a similar study in Egypt in 2002 done by Shalan et al. for laparoscopic pelvic surgery, who found that pain score and the analgesic dose required were lower in bupivacaine group. ${ }^{9}$ Hasaniya et al. in 2001 also studied the effect of preincisional bupivacaine instillation and concluded that the mean pain scores were lower as compared to controls at 4th and 24th hour postoperatively. ${ }^{10}$

Goldstein et al. did a study on 180 patients whom he divided into three groups and compared intraperitoneal $0.5 \%$ bupivacaine, $0.75 \%$ ropivacaine, and saline instillation, for postoperative pain relief. They found that local anesthetics gave significantly good pain relief with ropivacaine being better than bupivacaine in both analgesia and opioid-sparing effect. ${ }^{11}$ But ropivacaine was developed after bupivacaine was noted to be associated with increased risk of cardiac arrest, particularly in pregnant women, and is no longer generally used. ${ }^{12}$ Levobupivacaine is an S-isomer of racemic bupivacaine that has recently been introduced as a promising long-acting local anesthetic with lower toxicity than bupivacaine. $^{13}$

There were some studies that used bupivacaine after the surgery to assess the effect on postoperative pain. Bhardwaj et al. conducted a study of patients undergoing laparoscopic cholecystectomy. He instilled $20 \mathrm{~mL} 0.5 \%$ bupivacaine at the end of surgery in the Trendelenburg position. Postoperatively they assessed the pain score among other things, and they found that it reduced postoperative cholecystectomy pain and analgesic consumption. ${ }^{14}$

So, it has been seen that there are conflicting results in the different studies that have been done so far as there is still no consensus on the dosage, timing, and type of the local anesthetic drug to be administered.

Local anesthetics are associated with toxicity, which is doserelated. Thus, the amount of local anesthetics must be standardized not only for maximum efficacy but also to reduce drug-related toxicity. Neurological toxicity is a manifestation of the cerebral concentration of local anesthetic, and it is thus, caused by direct intravascular injection or rapid absorption. The maximally tolerated dose before manifestation of central nervous system toxicity is $12-25 \%$, which is much higher than the usual dose that is used for local infiltration. ${ }^{15,16}$

Besides local anesthetics infiltration and installation and reduction in troche size to $<10 \mathrm{~mm}$, there have been continuous efforts to improve postoperative pain management, following laparoscopic surgery by newer approach including single-incision 
laparoscopic surgery (SILS) and natural orifice transluminal endoscopic surgery (NOTES). These newer techniques are associated with far less postoperative pain scores and no or barely visible scar, faster recovery, and fewer wound-related complications like infection and incisional hernia and less hospital stay. But they are associated with a high cost of instruments, increased operative time, long learning curve, and insufficient data on intraoperative and postoperative complications. ${ }^{17}$ So, further works need to be done on these newer procedures, which may be the future of minimal access surgery with nonexistent postoperative pain.

\section{Limitations of the Study}

The limitation of this study is that this was conducted in a single center in Dhaka over a designated period. There should a multicenter, double-blinded randomized study with a larger sample size in the future to find out the efficacy of local bupivacaine, to reduce postoperative pain following laparoscopy. So, it is advisable to interpret the study results with caution.

\section{Conclusion}

To conclude, bupivacaine injection into the trocar site during diagnostic laparoscopy did not offer a significant reduction of postoperative pain in the present study. Further randomized trials are needed to evaluate the benefits of local anesthetic for postoperative pain reduction following laparoscopy.

\section{References}

1. Rawal N, Allvin R, Amilon A. Postoperative analgesia at home after ambulatory hand surgery: a controlled comparison of tramadol, metamizol and paracetamol. Anesth Analg 2001;92(2):347-351. DOI: 10.1213/00000539-200102000-00013.

2. Paul FW. The changing role of non-opioid analgesic techniques in the management of postoperative pain. Anesth Analg 2005; 101(5 Suppl):S5-S22. DOI: 10.1213/01.ane.0000177099.28914.a7.

3. Bisgaard T. Analgesic treatment after laparoscopic cholecystectomy. Anesthesiology 2006;104(4):835-846. DOI: 10.1097/00000542200604000-00030.

4. Vadivelu N, Mitra S, Schermer E, et al. Preventive analgesia for postoperative pain control: a broader concept. Local Reg Anesth 2014;7:17-22. DOI: 10.2147/LRA.S62160.
5. American Society of Hospital Pharmacists. Committee on Pharmacy and Pharmaceuticals. Hamilton Press; 1996.

6. Malhotra N, Chanana C, Roy KK, et al. To compare the efficacy of two doses of intraperitoneal bupivacaine for pain relief after operative laparoscopy in gynecology. Arch Gynecol Obstet 2007;274(4): 323-326. DOI: 10.1007/s00404-007-0337-1.

7. Chundrigar T, Hadges AR, Morris R, et al. Intraperitoneal bupivacaine for effective pain relief after laparoscopic cholecystectomy. Ann R Coll Surg Engl 1993;75(6):437-439.

8. Agrawal S, Pai S. Evaluation of postoperative pain relief with intra-peritoneal bupivacaine instillation in laparoscopic cholecystectomy - a randomized control study. Int Surg J 2017;4:1195-1200. DOI: 10.18203/2349-2902.isj20170987.

9. Shalan $\mathrm{H}$, Badaway $A$, Yousef $H$, et al. Effect of intraperitoneal bupivacaine on post-operative pain following laparoscopic pelvic surgery. Gynaecol Endosc 2002;11(6):371-375. DOI: 10.1111/j.13652508.2002.00557.x.

10. Hasaniya N, Zayed F, Faiz $\mathrm{H}$, et al. Pre-insertion local anesthesia at the trocar site improves peri-operative pain and decreases costs of laparoscopic cholecystectomy. Surg Endosc 2001;15(9):962-964. DOI: $10.1007 / \mathrm{s} 004640000294$.

11. Goldstein A, Grimault P, Henique A, et al. Preventing postoperative pain by local anesthetic instillation after laparoscopic gynecologic surgery-a placebo-controlled comparison of bupivacaine and ropivacaine. Anaesth Analg 2000;91(2):403-407. DOI: 10.1213/00000539-200008000-00032.

12. Ozmen S, Ozmen OA, Kasapoglu F. Effects of levo-bupivacaine v. bupivacaine infiltration on postoperative analgesia in pediatric tonsillectomy patients: a randomized, double-blind, placebocontrolled study. Ann Otol Rhinol Laryngol 2011;120(7):489-493. DOl: 10.1177/000348941112000712.

13. Cantore F, Boni L, Di Giuseppe M, et al. Pre-incision local infiltration with levobupivacaine reduces pain and analgesic consumption after laparoscopic cholecystectomy: a new device for day-case procedure. Int J Surg 2008;6(Suppl 1):S89-S92. DOI: 10.1016/j.ijsu.2008.12.033.

14. Bhardwaj N, Sharma V, Chari P. Intraperitoneal bupivacaine instillation for postoperative pain relief after laparoscopic cholecystectomy. Indian J Anaesth 2002;46(1):49-52.

15. Scott DB, Lee A, Fagan D. Acute toxicity of ropivacaine compared with that of bupivacaine. Anesth Analg 1989;69:563-569. DOI: 10.1213/00000539-198911000-00003.

16. Gutton C, Bellefleur JP, Puppo S, et al. Lidocaine $v$. ropivacaine for perineal infiltration post-episiotomy. Int J Gynaecol Obstet 2013;122(1):33-36. DOI: 10.1016/j.ijgo.2013.01.028.

17. Cotirlet A, Nedelcu M, Popa E, et al. Single incision laparoscopic cholecystectomy. Chirurgia (Bucur) 2014;109:769-773. 